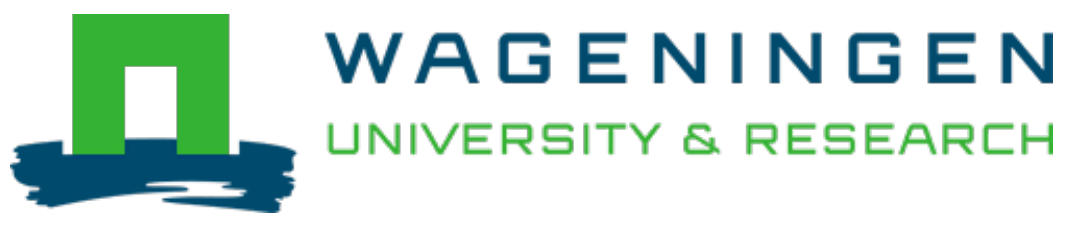

\title{
Vertical Farming: Moving from Genetic to Environmental Modification
}

Trends in Plant Science

SharathKumar, Malleshaiah; Heuvelink, Ep; Marcelis, Leo F.M.

https://doi.org/10.1016/j.tplants.2020.05.012

This article is made publicly available in the institutional repository of Wageningen University and Research, under the terms of article $25 \mathrm{fa}$ of the Dutch Copyright Act, also known as the Amendment Taverne. This has been done with explicit consent by the author.

Article $25 \mathrm{fa}$ states that the author of a short scientific work funded either wholly or partially by Dutch public funds is entitled to make that work publicly available for no consideration following a reasonable period of time after the work was first published, provided that clear reference is made to the source of the first publication of the work.

This publication is distributed under The Association of Universities in the Netherlands (VSNU) 'Article $25 \mathrm{fa}$

implementation' project. In this project research outputs of researchers employed by Dutch Universities that comply with the legal requirements of Article $25 \mathrm{fa}$ of the Dutch Copyright Act are distributed online and free of cost or other barriers in institutional repositories. Research outputs are distributed six months after their first online publication in the original published version and with proper attribution to the source of the original publication.

You are permitted to download and use the publication for personal purposes. All rights remain with the author(s) and / or copyright owner(s) of this work. Any use of the publication or parts of it other than authorised under article $25 \mathrm{fa}$ of the Dutch Copyright act is prohibited. Wageningen University \& Research and the author(s) of this publication shall not be held responsible or liable for any damages resulting from your (re)use of this publication.

For questions regarding the public availability of this article please contact openscience.library@,wur.nl 
universal and gives almost unlimited possibilities for introducing point mutations and small indels with useful efficiencies, without the need to co-deliver a repair template. Further improvement of this system should focus on increasing prime editing efficiency, mainly by testing different RTs and pegRNA designs. To overcome the limitation of the editing window, the use of different Cas proteins with different PAM requirements will allow the complex to be brought to the correct location to introduce the desired modification. Also, a detailed analysis on the specificity of this technique in plants and comparative analysis with other available methods for plant genome modification, in the aspect of the off-target edits, is required. Finally, to increase the versatility of the prime editing technique, it is necessary to improve the size of introduced indels and reduce the byproducts editing.

\footnotetext{
${ }^{1}$ University of Silesia in Katowice, Faculty of Natural Sciences, Institute of Biology, Biotechnology and Environmental Protection, Jagiellonska 28, 40-032 Katowice, Poland

${ }^{2}$ Department of Physiology and Cell Biology, Leibniz Institute of Plant Genetics and Crop Plant Research (IPK), Seeland, Germany

${ }^{3}$ Division of Molecular Biology, Centre of the Region Hana for Biotechnological and Agriculture Research, Faculty of Science, Palacký University, Olomouc, Czech Republic

${ }^{*}$ Correspondence:

marek.marzec@us.edu.pl (M. Marzec).

https://doi.org/10.1016/j.tplants.2020.05.008

(c) 2020 Elsevier Ltd. All rights reserved.
}

References

1. Jinek, M. et al. (2012) A programmable dual-RNA-guided DNA endonuclease in adaptive bacterial immunity. Science 337, 816-821

2. Cong, L. et al. (2013) Multiplex genome engineering using CRISPR/Cas systems. Science 339, 819-823

3. Marzec, M. and Hensel, G. (2019) More precise, more universal and more specific - the next generation of RNAguided endonucleases for genome editing. FEBS J. 286, 4657-4660

4. Rees, H.A. and Liu, D.R. (2018) Base editing: precision chemistry on the genome and transcriptome of living cells. Nat. Rev. Genet. 19, 770-788

5. Anzalone, A.V. et al. (2019) Search-and-replace genome editing without double-strand breaks or donor DNA. Nature 576, 149-157

6. Lin, Q. et al. (2020) Prime genome editing in rice and wheat. Nat. Biotechnol. 38, 582-585

\section{Forum}

Vertical Farming: Moving from Genetic to Environmental Modification
Malleshaiah SharathKumar (1), ${ }^{1, *}$ (₫) Ep Heuvelink $\mathbb{C}^{1}{ }^{1}$ and Leo F.M. Marcelis $\mathbb{1}^{1, *, @}$

Vertical farming (VF) is a novel plant production system that allows local production of high-quality fruits and vegetables for rapidly growing cities. VF offers a myriad of opportunities to move from genetic to environmental modification and to produce crops of guaranteed quality and quantity independent of weather, soil conditions, or climate change.

Climate change, scarcity of fresh water, intensive pesticide use, mineral resource depletion, and rapidly urbanizing societies challenge current plant production systems. Furthermore, there is increasing demand of consumers for high-quality fresh produce that is safe, healthy, tasty, and sustainably produced in or near cities. $\mathrm{VF}$ is a novel, climate-smart solution that could potentially address these demands.

\section{What Is VF?}

VF is a multilayer indoor plant production system (Figure 1) in which all growth factors, such as light, temperature, humidity, carbon dioxide concentration $\left(\left[\mathrm{CO}_{2}\right]\right)$, water, and nutrients, are precisely controlled to produce high quantities of high-quality fresh produce yearround, completely independent of solar light and other outdoor conditions [1]. This control can be fully automated by using sensors and imaging techniques in combination with crop simulation models and artificial intelligence.

VF is extremely sustainable with respect to water, fertilizers, and land use, although high energy use and investment costs remain a challenge. Furthermore, this system can run without pesticides by preventing pests and diseases from entering VF by the adoption of a high level of hygiene, continuous monitoring, and non-chemical disinfection (UV, $\mathrm{O}_{3}$, heat).

The level of the individual environmental factors and their combinations differ from those in conventional production systems. Consequently, the processes governing growth and quality occur at different rates. Therefore, to realize VF as an alternative sustainable production system, advances in plant science are paramount. We discuss the opportunities to regulate plant processes relevant to VF (Figure 2).

\section{Photobiology}

Manipulation of the spectrum, intensity, and timing of light offers opportunities to regulate physiological processes [2]. A range of photoreceptors (see Glossary) exists that makes plants sensitive to UV-A, UV-B (UVR8), blue (cryptochromes, phototropins, zeitlupes), and red:far red (phytochromes). Mistakenly, green light has often been neglected [3]. Effects of green light are probably mediated by cryptochromes or perhaps by an as-yet-unknown receptor. Knowledge on the signaling role of the individual photoreceptors is rapidly increasing [4]. However, the interplay among photoreceptors as well as crosstalk with other signaling pathways needs more attention.

In $V F$, dynamic lighting opens many possibilities for the control of yield and quality by exploiting the circadian clock, 
a master regulator of plant physiology and development with various transcriptional and translational feedback loops [5]. Opportunities for changing the spectrum during the light period should be further explored. For instance, the spectrum could be oriented at the start of the light period towards opening of stomates (blue-red), in the middle of the light period towards photosynthesis (high fraction of red), and at the end of light period towards stem elongation (far-red) or floral induction (blue). Floral induction in short-day plants might be possible in long days when specific spectra are chosen, as we have shown for chrysanthemum (Chrysanthemum morifolium). Besides changing the spectrum and intensity throughout the light period, in VF light-dark cycles do not need to remain fixed at exactly $24 \mathrm{~h}$. Changing the diel cycle length offers new possibilities to consider different durations of the light and dark period. However, the duration of the light and dark period must be aligned with the endogenous periodicity of the plant if optimal growth is to occur.

\section{Photomorphogenesis}

Effects of the light spectrum on crop photosynthesis usually depend to a larger extent on morphology than on leaf photosynthesis, as morphology determines the amount of light intercepted. Increased absorption of light and more uniform distribution over the leaves can profoundly improve yield. Spectral effects on dry matter partitioning can improve the harvest index. To improve yield, a holistic approach is essential to balance morphogenesis and metabolic processes [6]. Two hormone systems (florigen-antiflorigen and gibberellinDELLA) [7] that universally control flowering and plant architecture offer a great opportunity to modify plant traits suitable for VF. Recently, phytochrome interacting factors (PIFs) emerged as central regulators of photomorphogenic development in arabidopsis (Arabidopsis thaliana). Still, it is largely unknown how PIFs contribute to growth and development in crops.
Photosynthesis

The spatial and temporal distribution of the light spectrum and the intensity are important to optimize photosynthesis at both leaf and canopy level. Enhancing photosynthesis is essential, but makes sense only if source and sink strength are balanced at the whole-plant level. Although the leaf photosynthetic efficiency of green light is usually lower than that of red and blue due to higher reflection, it penetrates deeper into leaves and canopies, which can be beneficial for crop photosynthesis. Additionally, far-red may play a role in photosynthesis and has been proposed to be photosynthetically active radiation [8]. VF enables us to grow plants at continuously saturating $\left[\mathrm{CO}_{2}\right]$, whereas, so far, most research has been conducted at ambient or moderately elevated $\left[\mathrm{CO}_{2}\right]$. Saturating $\left[\mathrm{CO}_{2}\right]$ and its positive interaction with temperature and light intensity requires more attention. In VF, 24-h continuous lighting is theoretically preferred to maximize photosynthesis; however, in most crops this disturbs their metabolism.

\section{Secondary Metabolites}

LED lighting provides a unique tool to control secondary metabolites for enhanced nutraceutical, organoleptic, and/or dietary value. Often it is sufficient to apply the lighting treatment shortly before harvest. Biosynthesis and breakdown of secondary metabolites depends on light-regulated transcriptional factors; for instance, R2R3MYB for phenylpropanoids [9] and phytoene synthase activity (PSY) for carotenoids [10]. Furthermore, these effects of light can be directly linked to photosynthesis and respiration or indirectly to subsequent effects on sugar availability [11]. The sugars can serve as substrates and signaling molecules for secondary metabolite biosynthesis.

\section{Thermomorphogenesis}

VF requires compact plants; this can be achieved by specific diel temperature patterns (higher night than day temperature) or the light spectrum. We now know that
Glossary

Aeroponics: technique of growing plants in a soilless system with the roots in an air or mist environment.

Biofortification: methodology to increase the concentration and/or the bioavailability of nutrients in crops, especially the micronutrients that are not present or present in low amounts in plants but are valuable for human nutrition and health.

Circadian clock: endogenous timekeeper that helps plants to anticipate the day/night cycle. The clock integrates endogenous and external cues to coordinate growth and developmental processes; also referred to as the biological clock.

Continuous lighting: continuous (24 h) supply of light without darkness.

Dynamic lighting: changing the spectrum and intensity dynamically (in a defined pattern) depending on the time of the day or the growth stage of the plant. Hydroponics: technique of growing plants in a soilless system with the roots in a substrate (e.g., perlite, stonewool) or without a substrate directly in nutrient solution (e.g., nutrient film technique, deep flow systems).

Photomorphogenesis: light-induced morphological and developmental responses.

Photoreceptors: light-sensing proteins with a chromophore molecule allowing them to sense and respond to specific wavelengths of light. Examples include phytochromes, cryptochromes, phototropins, zeitlupes, and UV RESISTANCE LOCUS 8 (UVR8). Secondary metabolites: wide group of phytochemicals that are biosynthetically derived from primary metabolites that appear to have no direct function in growth and development. Examples include carotenoids, phenylpropanoids (flavonoid, anthocyanins, ascorbic acid, antioxidants, and essential oils). Many secondary metabolites contribute to the quality of fruits and vegetables (e.g., color, aroma, taste, nutritional value).

Sink strength: competitive ability of an organ to attract assimilates.

Source strength: assimilation rate of $\mathrm{CO}_{2}$ by the plant into structural and non-structural dry matter. Speed breeding: indoor plant growing technique to accelerate plant life cycle from seed to seed by tightly controlling all environmental factors, especially light and temperature. This shortening of the generation time contributes to the faster development of new cultivars.

Thermomorphogenesis: temperature-induced morphological and developmental responses. Tipburn: physiological disorder causing necrosis at the leaf margins and tips of rapidly growing young leaves associated with a localized calcium deficiency in the specific plant tissue.

PhyB acts as a thermosensor and that the PIF4 transcription factor serves as a central regulator of thermomorphogenesis [12]. Therefore, morphogenesis needs to be 


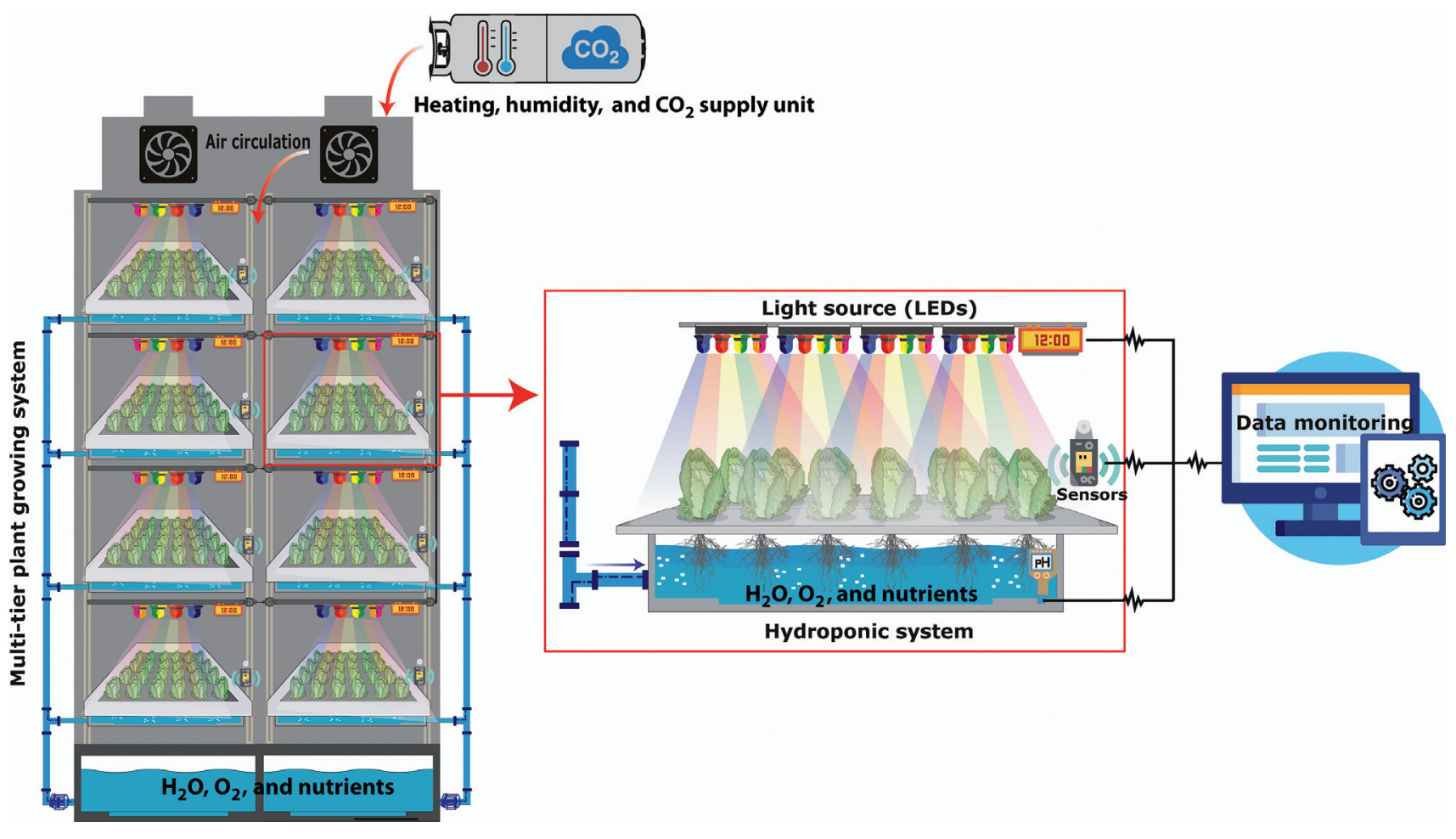

Figure 1. Set up of a Vertical Farm. A multilayer indoor plant growing system with an automated control system regulating the shoot environment (LED light, temperature, humidity, $\left[\mathrm{CO}_{2}\right]$, air flow) and soilless root environment ( $\mathrm{EC}, \mathrm{pH}$, concentration of nutrients and $\mathrm{O}_{2}$, and root temperature).

\section{Plant architecture and growth}

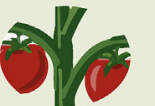

Dwarf phenotype (short internodes) Uniform in stature, shape, and color

High photosynthesis

Rapid growth and development

High harvest index

Easy to harvest

Small fibrous root system

\section{Light source (LEDs)}

(1)
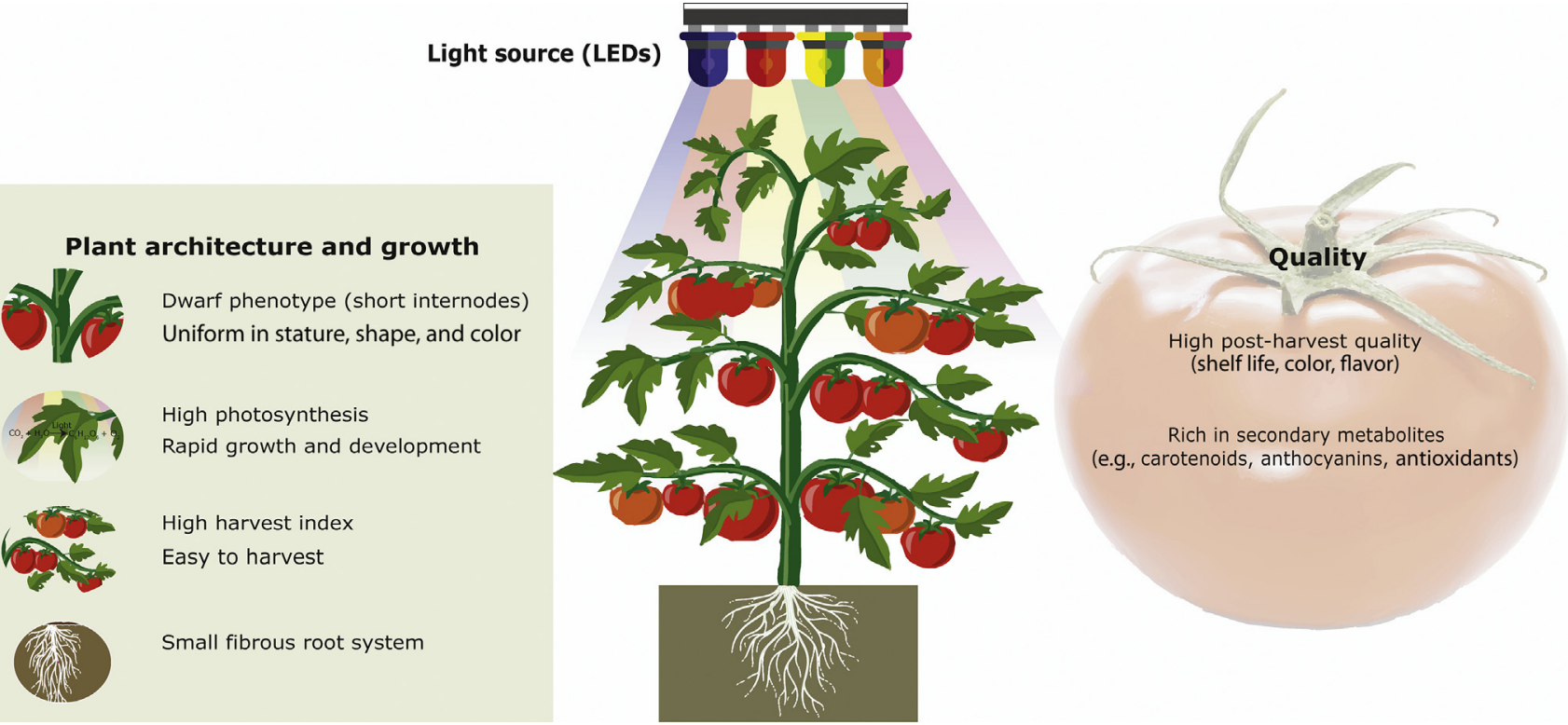
dealt with in an integrated way by combining the light spectrum, photoperiod, and temperature. Temperature, like other growth conditions, should not be constant but should be adapted to specific plant developmental stages for optimal productivity and quality and should be used to balance source and sink strength.

\section{Hydroponics}

Hydroponics and aeroponics ensure that water and nutrients are readily available to the roots. In VF, a small root system is optimal as it allows the plant to invest more in shoot biomass. Optimal $\mathrm{O}_{2}$ levels and root zone temperatures help to optimize water and nutrient uptake. Further understanding of temperature regulation of root function and structure, may contribute to improved plant productivity and quality. In hydroponics, the availability of nutrients to the roots can be adapted rapidly. This could, for instance, be used to restrain the nitrate content in edible plant tissues or for biofortification with microelements beneficial for humans, such as selenium and iodine [13]. Despite good calcium availability to roots, calcium-related physiological disorders like 'tipburn' often occur in VF. This seems related to high growth rates and low local transpiration in the plant (aggravated by high air humidity and low wind speed). Theories related to calcium transport and reactive oxygen species need to be integrated to understand this disorder.

\section{Breeding and Genetics}

For VF, breeders need to focus less on (a)biotic stress resistance. Thus, the tradeoff between growth versus defense dilemma is eliminated. Dwarf, fast-growing, easy-toharvest, high-yielding with enhanced quality phenotypes are ideal [14]. Recently, the genes responsible for traits such as dwarf and rapid and precocious flowering were identified in tomato (Solanum lycopersicum) and groundcherry (Physalis grisea) [15].
However, to date no cultivars have been bred for VF. A strong interaction between genotype and environment $(G \times E)$ offers a great potential to improve cultivars, but also implies that there is not one ideal genotype possible for VF. It is important that the genetic and environmental improvements are tuned to each other. VF offers possibilities to shorten the generation time and allows multiple crop generations per year, leading to 'speed breeding'.

\section{Concluding Remarks}

VF allows precise control of physiological and developmental processes in plants by the accurate management of growth conditions, enabling us to move from genetic to environmental modification to advance plant productivity and quality. To make VF successful, mechanistic understanding of plant functioning is vital. Concurrently, the introduction of VF as a novel plant production system will boost fundamental plant science.

\section{Acknowledgments}

We thank Sander van Delden (hydroponics section), Ernst Woltering (secondary metabolites section), and Elias Kaiser (complete manuscript) for their critical reading and feedback.

${ }^{1}$ Horticulture and Product Physiology, Wageningen University and Research, PO Box 16, 6700, AA, Wageningen, The Netherlands

\section{${ }^{*}$ Correspondence:}

sharath.malleshaiah@wur.nl (M. SharathKumar) and

leo.marcelis@wur.nl (L.F.M. Marcelis).

${ }^{\circledR}$ Twitter: @LeoMarcelis (L.F.M. Marcelis)

https://doi.org/10.1016/j.tplants.2020.05.012

(c) 2020 Elsevier Ltd. All rights reserved.

\section{References}

1. Kozai, T. et al. (2020) Plant Factory: An Indoor Vertical Farming System for Efficient Quality Food Production, Academic Press

2. Pattison, P.M. et al. (2018) LEDs for photons, physiology and food. Nature 563, 493-500

3. Smith, H.L. et al. (2017) Don't ignore the green light: exploring diverse roles in plant processes. J. Exp. Bot. 68, 2099-2110

4. Sanchez, S.E. et al. (2020) Light perception: a matter of time. Mol. Plant 13, 363-385

5. Sanchez, S.E. and Kay, S.A. (2016) The plant circadian clock: from a simple timekeeper to a complex developmental manager. Cold Spring Harb. Perspect. Biol. 8, a027748
6. Fernie, A.R. et al. (2020) Synchronization of developmental, molecular and metabolic aspects of source-sink interactions. Nat. Plants 6, 55-66

7. Eshed, Y. and Lippman, Z.B. (2019) Revolutions in agriculture chart a course for targeted breeding of old and new crops. Science 366, eaax0025

8. Zhen, S. and Bugbee, B. (2020) Far-red photons have equivalent efficiency to traditional photosynthetic photons: implications for redefining photosynthetically active radiation. Plant Cell Environ. 43, 1259-1272

9. Liu, J. et al. (2015) MYB transcription factors as regulators of phenylpropanoid metabolism in plants. Mol. Plant 8 , 689-708

10. Llorente, B. et al. (2017) Illuminating colors: regulation of carotenoid biosynthesis and accumulation by light. Curr. Opin. Plant Biol. 37, 49-55

11. Ntagkas, N. et al. (2018) Light regulates ascorbate in plants: an integrated view on physiology and biochemistry. Environ. Exp. Bot. 147, 271-280

12. Casal, J.J. and Balasubramanian, S. (2019) Thermomorphogenesis. Annu. Rev. Plant Biol. 4, 321-346

13. Sambo, P. et al. (2019) Hydroponic solutions for soilless production systems: issues and opportunities in a smart agriculture perspective. Front. Plant Sci. 10, 923

14. Folta, K.M. (2019) Breeding new varieties for controlled environments. Plant Biol. 21, 6-12

15. Kwon, C. et al. (2020) Rapid adaptation of Solanaceae fruit crops for urban agriculture. Nat. Biotechnol. 38, 182-188

\section{Forum}

\section{Pericyclic versus Endodermal Lateral Roots: Which Came First?}

Steffen Vanneste ${ }^{1,2,3}$ and Tom Beeckman ${ }^{1,2,4, *}$

Digging into the limited literature on lateral root (LR) formation in early vascular plants, we came to the novel conclusion that the pericycle, rather than the endodermis as commonly assumed, represents the ancestral tissue that was evolutionarily recruited to form LRs.

Roots represent crucial evolutionary inventions for plants that have been indispensable in their conquest of land conditions. They provide the means to explore large volumes of soil for water and nutrients and to establish symbiosis with soil microbes and provide a solid anchoring point allowing vertical growth. Fossil records show that the original rooting 